\title{
Searching for Novel Candidate Biomarkers of RLS in Blood by Proteomic Analysis
}

\author{
Stefania Mondello' \\ Firas H Kobeissy (D) ${ }^{2}$ \\ Yehia Mechref ${ }^{2}$ \\ Jingfu Zhao ${ }^{3}$ \\ Samer El Hayek ${ }^{4}$ \\ Kazem Zibara $\left.{ }^{5}\right)^{5}$ \\ Monica Moresco $0^{6,7}$ \\ Giuseppe Plazzi (iD ${ }^{6}$ \\ Filomena II Cosentino ${ }^{8}$ \\ Raffaele Ferri $\mathbb{D}^{8}$ \\ 'Department of Biomedical and Dental \\ Sciences and Morphofunctional Imaging, \\ University of Messina, Messina, Italy; \\ ${ }^{2}$ Faculty of Medicine, American \\ University of Beirut Medical Center, \\ Beirut, Lebanon; ${ }^{3}$ Department of \\ Chemistry and Biochemistry, Texas Tech \\ University, Lubbock, TX, 79409, USA; \\ ${ }^{4}$ Department of Psychiatry, American \\ University of Beirut, Beirut, Lebanon; \\ ${ }^{5}$ Department of Biology, Faculty of \\ Sciences-I, PRASE, DSST, Lebanese \\ University, Beirut, Lebanon; ${ }^{6}$ Department \\ of Biomedical and Neuromotor Sciences, \\ Alma Mater Studiorum, University of \\ Bologna, Bologna, Italy; ${ }^{7}$ IRCCS Istituto \\ delle Scienze Neurologiche di Bologna, \\ Bologna, Italy; ${ }^{8}$ Sleep Research Centre, \\ Oasi Research Institute - IRCCS, Troina, \\ Italy
}

Correspondence: Raffaele Ferri Sleep Research Centre, Oasi Research Institute - IRCCS, Troina, 940I8, Italy

$\mathrm{Tel}+390935936 \mathrm{III}$

Fax +390935 936231

Email rferri@oasi.en.it
Purpose: We performed comparative proteomic analyses of blood of patients with RLS and healthy individuals aiming to identify potential biomarker and therapeutic target candidate for RLS.

Patients and Methods: Blood serum samples from 12 patients with a clinical diagnosis of RLS ( 8 females and 4 males, with a mean age of 68.52 years) and 10 healthy controls (5 females and 5 males, with a mean age of 67.61 years) underwent proteomic profiling by liquid chromatography coupled with tandem mass spectrometry. Pathway analysis incorporating protein-protein interaction networks was carried out to identify pathological processes linked to the differentially expressed proteins.

Results: We quantified 272 proteins in patients with RLS and healthy controls, of which 243 were shared. Five proteins - apolipoprotein C-II, leucine-rich alpha-2-glycoprotein 1, FLJ92374, extracellular matrix protein 1, and FLJ93143 - were substantially increased in RLS patients, whereas nine proteins - vitamin D-binding protein, FLJ78071, alpha-1-antitrypsin, CD5 antigenlike, haptoglobin, fibrinogen alpha chain, complement factor $\mathrm{H}$-related protein 1, platelet factor 4 , and plasma protease $\mathrm{C} 1$ inhibitor - were decreased. Bioinformatics analyses revealed that these proteins were linked to 1) inflammatory and immune response, and complement activation, 2) brain-related development, cell aging, and memory disorders, 3) pregnancy and associated complications, 4) myocardial infarction, and 5) reactive oxygen species generation and subsequent diabetes mellitus.

Conclusion: Our findings shed light on the multifactorial nature of RLS and identified a set of circulating proteins that may have clinical importance as biomarkers and therapeutic targets.

Keywords: idiopathic restless legs syndrome, biomarkers, LC-MS/MS, proteome, interactome

\section{Introduction}

Restless leg syndrome (RLS) ${ }^{1}$ is a relatively common neurologic sleep-related movement disorder, with a reported prevalence ranging from $5 \%$ to $10 \%$ in the general population, making it the most common movement disorder and one of the most common sleep disorders. ${ }^{2,3}$ RLS often impairs sleep and has a significant negative impact on the health-related quality of life; ${ }^{1,2,4}$ hypothalamic-pituitaryadrenal system activation in RLS may also contribute to cerebrovascular disease and stroke. ${ }^{5,6}$

Still relatively little is known about the pathophysiology of RLS. ${ }^{7,8}$ Early imaging $^{9-11}$ and pharmacological studies ${ }^{12-15}$ have demonstrated a dysregulation of central dopaminergic neurotransmission, empirically confirmed by the 
improvement following treatment with dopamine agonists. $^{16,17}$ Nevertheless, objective measures of dopamine function are not clinically available, and results of imaging studies of dopamine receptors are inconsistent and contradictory. ${ }^{18,19}$ Human evidence has implied an aberrant central nervous system iron metabolism in the pathophysiology of RLS, though the underlying mechanism remains unclear, and other non-dopaminergic pathways may also play a crucial role. ${ }^{19-23}$

To date, the diagnosis of RLS primarily relies on its clinical features, while self-administered surveys can be used for screening. ${ }^{24}$ This approach, however, presents important limitations with high risk of misdiagnosis and delays, hampering appropriate patient management and timely initiation of therapeutic interventions. ${ }^{25}$

Disease states and pathological dysfunctions may be reflected in substantial changes in the concentrations of proteins in the blood, generating a disease-specific molecular signature. ${ }^{26,27}$ Mass spectrometry-based proteomics represent a powerful tool to explore altered cellular proteomes, opening up new avenues for better understanding of disease pathophysiology and for biomarker discovery. ${ }^{28-31}$ Efforts have been made to identify biomarkers using this approach. Nonetheless, research is still in its infancy and data are scarce. Only few proteomic studies were previously conducted, one using cerebrospinal fluid $(\mathrm{CSF})^{32}$ and other blood plasma. ${ }^{33-36}$ The latter represents a better resource for biomarkers, as they should be not only highly sensitive and specific but also easily attainable. $^{37}$

In this study, we performed comparative proteomic analyses of serum samples of patients with RLS and healthy individuals to identify biomarker and therapeutic target candidate for RLS. We also used bioinformatic analysis to elucidate pathobiological processes and dysregulated pathways that underlie the observed molecular phenotype.

\section{Patients and Methods}

\section{Study Participants}

Patients with a clinical diagnosis of idiopathic RLS were recruited from the Sleep Research Centre of the Oasi Research Institute - IRCCS, Troina (Italy) and the Department of Neurology of the University of Bologna (Italy), between March 2017 and August 2017. Eligibility criteria included diagnosis of RLS and age 18 years or older. All patients underwent physical (including neurological) examination by an experienced physician, and diagnosis was made according to the International RLS Study Group diagnostic criteria ${ }^{1}$ by means of a semistructured clinical interview and a careful exclusion of RLS mimics. Specifically, a patient was considered to be affected by RLS if she/he met the five standard diagnostic criteria. Exclusion criteria included 1) a sleep disorder diagnosis (other than RLS); 2) neurological or psychiatric diagnosis; 3) major medical disorder; 4) use of any drug or medication for 3 weeks before the analysis; 5) previous iron supplementation. The disease severity was also assessed by means of the International RLS Study Group severity (IRLS) scale $^{38}$ : we only included patients with a moderate disease severity (IRLS $<25$, range between 15 and 24), most of them were being diagnosed for the first time and all had a disease duration $<10$ years. None of the patients was affected by iron-deficient anemia and none had ferritin levels $<50 \mu \mathrm{g} / \mathrm{L}$. Healthy participants served as controls.

The study was approved by the Oasi Research Institute Ethics Committee (no. 2018/07/18/CE-IRCCS-OASI/14). All participants provided written informed consent prior to participation in the study. All procedures were performed in accordance with the 1964 Helsinki declaration and its later amendments.

\section{Blood Sampling and Materials}

Serum samples were collected between 9 AM and noon. They were processed, aliquoted, and frozen at $-80^{\circ} \mathrm{C}$ according to standardized procedures. ${ }^{39}$ HPLC-gradient water purchased from Avantor Performance Materials (Center Valley, PA, USA) and HPLC-grade acetonitrile (ACN) were obtained from Fisher Scientific (Pittsburgh, PA, USA). Ammonium bicarbonate (ABC), DLdithiothreitol (DTT) and iodoacetamide (IAA) were produced from Sigma-Aldrich (St. Louis, MO). Formic acid was purchased from TCI America (Portland, OR, USA). Mass-spectrometry-grade Trypsin/Lys-C Mix was obtained from Promega (Madison, WI, USA).

\section{Depletion of High Abundance Proteins in Serum}

Multiple affinity removal column $(4.6 \times 100 \mathrm{~mm})$ was used to deplete the 14 most abundant proteins, namely albumin, $\mathrm{IgG}$, antitrypsin, IgA, transferrin, haptoglobin, fibrinogen, alpha 2-macroglobulin, alpha 1-acid glycoprotein, $\operatorname{IgM}$, apolipoprotein AI, apolipoprotein AII, complement C3 
and transthyretin. The affinity column was attached to the Dionex 3000 Ultimate $R S$ LC system (Dionex, Sunnyvale, CA, USA) with buffer A (Agilent, Santa Clara, CA, USA) as mobile phase A and buffer B (Agilent, Santa Clara, CA, USA) as mobile phase B. LC gradient stated in the manufacture's handbook was used for the depletion. A 30 $\mu \mathrm{L}$-aliquot of blood serum of each sample combined with $70 \mu \mathrm{L}$ of buffer A was subjected to depletion separately. The buffer of depleted blood serum was exchanged into $50 \mathrm{mM}$ ammonium bicarbonate $(\mathrm{pH}$ 8.0) using $5 \mathrm{KDa}$ MWCO $4 \mathrm{~mL}$ spin concentrator from Agilent (Santa Clara, CA, USA) following manufacture's instruction. The depletion process was necessary to decrease the high dynamic range of serum proteome, thus allowing the identification and quantitation of low abundant proteins.

\section{Tryptic Digestion}

Prior to tryptic digestion, the protein concentration was determined by the micro BCA protein assay kit following the protocol provided by the Thermo Scientific Pierce (Rockford, IL, USA). A 20- $\mu$ g aliquot of depleted serum proteins with $50 \mathrm{mM}$ ABC buffer added to $100 \mu \mathrm{L}$ was transferred to an Eppendorf tube. Thermal denaturation was performed at $80{ }^{\circ} \mathrm{C}$ for $20 \mathrm{~min}$. DTT and IAA with concentration of $200 \mathrm{mM}$ was prepared in $50 \mathrm{mM}$ ABC buffer. Proteins were first reduced by adding a $2.5-\mu \mathrm{L}$ aliquot of DTT solution and incubation at $60{ }^{\circ} \mathrm{C}$ for 45 $\min$. Next, the reduced proteins were alkylated by adding a $10-\mu \mathrm{L}$ aliquot of IAA solution and incubation at $37.5^{\circ} \mathrm{C}$ for $45 \mathrm{~min}$. The alkylation reaction was then quenched by adding a second $2.5-\mu \mathrm{L}$ aliquot of DTT and incubation at $37.5^{\circ} \mathrm{C}$ for $30 \mathrm{~min}$. A $0.8-\mu \mathrm{g}$ aliquot of trypsin was added to the reduced and alkylated sample, and then incubated at $37.5^{\circ} \mathrm{C}$ for $18 \mathrm{~h}$. The enzymatic digestion was quenched by adding a $0.5-\mu \mathrm{L}$ neat formic acid. Prior to liquid chromatography coupled with tandem mass spectrometry (LCMS/MS) analysis, the samples were speed-vacuum dried and resuspended in 2\% ACN/0.1\% formic acid.

\section{LC-MS/MS Analysis}

Analysis was performed on a Dionex 3000 Ultimate nanoLC system (Sunnyvale, CA, USA) interfaced to a LTQ OrbitrapVelos mass spectrometer (Thermo Scientific, Waltham, MA, USA) equipped with a nano-ESI source. For each sample, tryptic digests corresponded to $2 \mu \mathrm{g}$ of proteins were subjected to LC-MS/MS analysis. Samples were first online-purified using Thermo Scientific Acclaim PepMap100 C18 pre-column $(75 \mu \mathrm{m} \times 20 \mathrm{~mm}, 3 \mu \mathrm{m}, 100$
$\AA$ ). Next, the tryptic digests were separated using Thermo Scientific Acclaim PepMap100 C18 pre-column (75 $\mu \mathrm{m} \times$ $150 \mathrm{~mm}, 2 \mu \mathrm{m}, 100 \AA)$. The separation was achieved at a flow rate of $350 \mathrm{~nL} / \mathrm{min}$ in $120 \mathrm{~min}$, using following gradient: Solvent B was kept at 5\% for the first 10 min, increased from $5 \%$ to $20 \%$ over $55 \mathrm{~min}, 20-30 \%$ over $25 \mathrm{~min}, 30-50 \%$ over $20 \mathrm{~min}, 50-80 \%$ over $1 \mathrm{~min}$, kept at $80 \%$ for $4 \mathrm{~min}$, decreased from $80 \%$ to $5 \%$ over 1 min and maintained at 5\% over $4 \mathrm{~min}$. The solvent A contained $2 \% \mathrm{ACN}, 0.1 \% \mathrm{FA}$ and $97.9 \%$ water, while the solvent $\mathrm{B}$ is $0.1 \%$ formic acid in $\mathrm{ACN}$.

The LTQ OrbitrapVelos mass spectrometer was operated in data-dependent acquisition mode with two scan events. The first scan event was a full MS scan of 400$2000 \mathrm{~m} / \mathrm{z}$ with a resolution of 60,000 . The second MS event was a CID MS/MS scan repeated 10 times on 10 most intense ions selected from the first full MS scan with mass resolution of 7,500 and an isolation width of $3 \mathrm{~m} / \mathrm{z}$. Normalized collision energy (CE) was set to 35 with and activation $Q$ value of 0.250 and an activation time of $10 \mathrm{~ms}$.

\section{LC-MS/MS Data Analysis}

The LC-MS/MS data were analyzed by Max Quantversion 2.4 (Matrix Science Inc., Boston, MA). LC-MS/MS data were searched against Swiss Prot human database. Carbamidomethylation of cysteine was set as a fixed modification, while oxidation of methionine was set as a variable modification. The $\mathrm{m} / \mathrm{z}$ tolerance was set to 6 ppm and 0.5 Da for precursor and fragment ions, respectively, for the identification of peptides. Minimal peptide length was set to 7 with maximum of two missed cleavages. Only proteins with at least two peptides identified were considered. The "Matching-between-runs" function was enabled. Label-free quantification (LFQ) approach was employed and the LFQ intensities were used for subsequent data analysis.

\section{System Biology Analysis}

For protein interaction and pathway analysis, the Elsevier's Pathway Studio version 10.0 (Ariadne Genomics/Elsevier) was used to demonstrate relationships among differentially expressed protein candidates using the ResNetdatabase. In this regard, "Subnetwork Enrichment Analysis" (SNEA) algorithm was selected to extract statistically significant altered biological and functional pathways pertaining to each identified set of protein hits. 


\section{Statistical Analysis}

The statistical analysis was performed using Perseus version 1.5.5.0 (Max Planck Institute of Biochemistry, Munich, Germany) and GraphPad Prism 7 (GraphPad Software Company, La Jolla, CA, USA). For both peptide and protein identification, a false discovery rate (FDR) adjusted p-value (ie, q value) threshold of 0.01 was used. For the statistical analysis, SNEA utilizes the Fisher's statistical test to determine if there are nonrandom associations between two categorical variables organized by specific relationship (protein interaction and biological process). Specifically, SNEA starts by creating a central "seed" from all relevant entities in the database based on their relationship with the seed (eg, binding partners, expression targets, protein modification targets, regulation). The algorithm compares the sub-network distribution to the background distribution using one-sided MannWhitney $U$-Test, and calculates a p-value indicating the statistical significance of difference between two distributions. In our analysis, "GenBank" ID and gene symbols from each set were imported to the software to form an experimental data set.

\section{Results}

\section{Differentially Expressed Proteins in Patients with RLS Compared to Healthy Controls}

The study included 12 patients with a clinical diagnosis of RLS ( 8 females and 4 males, with a mean age of 68.52 years) and 10 healthy controls ( 5 females and 5 males, with a mean age of 67.61 years). There were no significant differences in age or sex composition between the two groups.

A total of 272 circulating proteins were identified and quantified (Supplementary Table S1). Of those, 250 were detected in the healthy controls and 246 in patients with RLS. Among the 243 shared proteins 14 proteins differ considerably, of which 5 were upregulated and 9 were downregulated in RLS compared to healthy controls. Table 1 shows the differentially expressed proteins with the biological processes and molecular functions.

\section{Global Interactome Maps and Enrichment Pathways Analysis for Patients with RLS}

We identified multiple altered pathways when using the 14 identified differentially expressed proteins in the patients with RLS. The interactome networks related to these proteins, along with their associated genes, are presented in Figure 1.

Figure 1A shows an intricate network of inflammation, associated with inflammatory response, immune response, and complement activation, connecting nine of the identified proteins, namely apolipoprotein C-II (APOC-II), vitamin D-binding protein (DBP), alpha-1-antitrypsin $\left(\mathrm{A}_{1} \mathrm{AT}\right)$, CD5 antigen-like (CD5L), haptoglobin (Hp), fibrinogen alpha chain (FGA), complement factor $\mathrm{H}$-related protein 1 (CFHR1), platelet factor 4 (PF4), and plasma protease $\mathrm{C} 1$ inhibitor.

Figure 1B displays a network associated with brain development and memory disorders. In this pathway, the differentially expressed $A_{1} A T$ is linked to cell aging, subsequently affecting neuronal development and contributing to the development of memory disorders.

Similarly, in Figure 1C, multiple proteins (ie, $\mathrm{A}_{1} \mathrm{AT}$, $\mathrm{Hp}, \mathrm{FGA}$, and plasma protease $\mathrm{C} 1$ inhibitor have been directly linked to myocardial infarction, via their interaction with pathways affecting the cardiovascular function and cerebrovascular circulation.

Figure 1D presents a network associated with diabetes mellitus and its related complications. In this pathway, the differentially expressed APOC-II, A AT, Hp, FGA, PF4, and Plasma protease $\mathrm{C} 1$ inhibitor are associated with the generation of reactive oxygen species, contributing to the pathophysiology of diabetes.

Finally, data in Figure 1E show the involvement of several differentially expressed proteins (DBP, $\mathrm{A}_{1} \mathrm{AT}, \mathrm{Hp}$, FGA, PF4, and Plasma protease $\mathrm{C} 1$ inhibitor in pregnancy and its related complications.

\section{Discussion}

We found 14 differentially expressed proteins in the blood of RLS patients compared to healthy controls. To understand the potential pathobiological and pathogenetic relevance of these proteins in RLS, we used several advanced bioinformatics tools that revealed five independent pathways and networks centered on inflammation/immune response, brain-related development, pregnancy, myocardial infarction, and oxidative stress (Figure 1). This analysis pointed to a multiplicity and diversity of pathophysiological mechanisms that may underlie and be active in this complex disorder.

Importantly, serum levels of APOC-II were found to be significantly upregulated in patients with RLS, ultimately increasing the risk of cardiovascular disease. ${ }^{40}$ To date, there is no reported association between APOC-II and 
Table I Table Displaying the Main Characteristics of the Differentially Expressed Proteins in Patients with RLS Compared to Healthy Controls

\begin{tabular}{|c|c|c|c|c|c|c|}
\hline Protein Name & Biological Process & Molecular Function & $\begin{array}{l}\text { Gene } \\
\text { Name }\end{array}$ & $\begin{array}{l}\text { Protein } \\
\text { ID }\end{array}$ & $\begin{array}{c}\text { Fold } \\
\text { Change }\end{array}$ & q-value \\
\hline \multicolumn{7}{|l|}{ Upregulated Proteins } \\
\hline Apolipoprotein C-II & Lipid metabolic process & $\begin{array}{l}\text { Binding, enzyme activator } \\
\text { activity }\end{array}$ & APOC2 & P02655 & 2.26 & $<0.0001$ \\
\hline $\begin{array}{l}\text { Leucine-rich alpha-2-glycoprotein } \\
\text { I }\end{array}$ & $\begin{array}{l}\text { Cellular process, } \\
\text { immune system process }\end{array}$ & Binding & $L R G I$ & P02750 & 1.97 & 0.0005 \\
\hline $\begin{array}{l}\text { FLJ92374, highly similar to Homo } \\
\text { sapiens C-type lectin domain } \\
\text { family 3, member B }\end{array}$ & - & - & - & B2R582 & 1.23 & 0.0118 \\
\hline Extracellular matrix protein I & Angiogenesis & $\begin{array}{l}\text { Binding, extracellular matrix } \\
\text { structural constituent }\end{array}$ & ECMI & Q16610 & 2.07 & 0.023 \\
\hline $\begin{array}{l}\text { FLJ93 I 43, highly similar to Homo } \\
\text { sapiens complement component } 7\end{array}$ & - & - & - & $\mathrm{B} 2 \mathrm{R} 6 \mathrm{WI}$ & 1.63 & 0.0464 \\
\hline \multicolumn{7}{|l|}{ Downregulated Proteins } \\
\hline Vitamin D-binding protein & Localization & Binding, transporter activity & GC & P02774 & 0.94 & $<0.0001$ \\
\hline $\begin{array}{l}\text { FLJ7807I, highly similar to Human } \\
\text { MHC class III complement } \\
\text { component C6 }\end{array}$ & - & - & - & A8K8Z4 & 0.54 & 0.0005 \\
\hline Alpha-I-antitrypsin & $\begin{array}{c}\text { Cellular process, acute } \\
\text { phase response }\end{array}$ & $\begin{array}{l}\text { Binding, catalytic activity, } \\
\text { molecular function regulator }\end{array}$ & SERPINAI & P01009 & 0.44 & 0.0006 \\
\hline CD5 antigen-like & $\begin{array}{l}\text { Immune system } \\
\text { process, apoptosis }\end{array}$ & Receptor activity & CD5L & O43866 & 0.73 & 0.0018 \\
\hline Haptoglobin & $\begin{array}{l}\text { Biological regulation, } \\
\text { cellular process, } \\
\text { response to stimulus }\end{array}$ & Binding, antioxidant activity & $H P$ & P00738 & 0.14 & 0.0051 \\
\hline Fibrinogen alpha chain & Cellular process & $\begin{array}{l}\text { Binding, structural molecule } \\
\text { activity, extracellular matrix } \\
\text { structural constituent }\end{array}$ & FGA & P0267I & 0.57 & 0.0216 \\
\hline $\begin{array}{l}\text { Complement factor H-related } \\
\text { protein I }\end{array}$ & $\begin{array}{l}\text { Immune system } \\
\text { process, viral process }\end{array}$ & Binding & CFHRI & Q0359I & 0.58 & 0.0247 \\
\hline Platelet factor 4 & $\begin{array}{l}\text { Immune system } \\
\text { process, localization, } \\
\text { response to stimulus }\end{array}$ & $\begin{array}{l}\text { Binding, molecular function } \\
\text { regulator, molecular transducer } \\
\text { activity }\end{array}$ & PF4 & P02776 & 0.59 & 0.041 \\
\hline Plasma protease $\mathrm{Cl}$ inhibitor & Cellular process & $\begin{array}{l}\text { Binding, catalytic activity, } \\
\text { molecular function regulator }\end{array}$ & SERPINGI & P05I55 & 0.73 & 0.0453 \\
\hline
\end{tabular}

RLS; nevertheless, a higher prevalence of hypercholesterolemia has been previously noted in these patients, ${ }^{41,42}$ even if the mechanisms might be complex and influenced by comorbidities. ${ }^{43}$ In a study by Patton et al, proteomic analysis of CSF samples from 5 patients with RLS identified a differential downregulation of another apolipoprotein, APOA-I, ${ }^{32}$ while a recent work investigating serum proteome of 6 patients ${ }^{35}$ reported substantial upregulation 

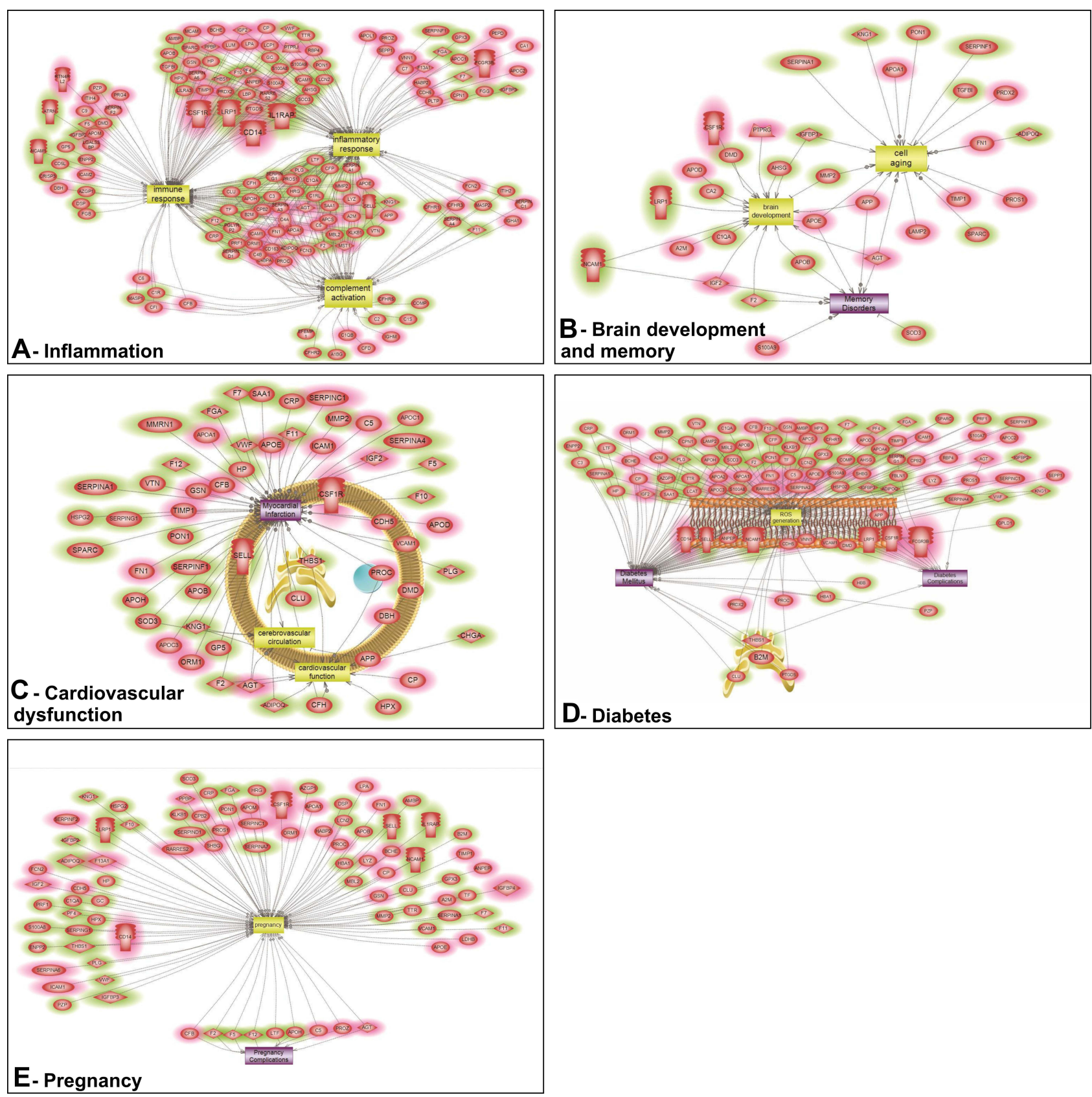

Figure I Interactome networks describing pathways associated with inflammatory response, immune response, and complement activation (A), brain-related development, cell aging, and memory disorders (B), myocardial infarction-related pathways (C), reactive oxygen species generation and subsequent diabetes mellitus (D), and pregnancyrelated pathways and their associated complications $(\mathbf{E})$, based on the differentially expressed proteins in patients with RLS. Red $=$ upregulated; green $=$ downregulated; mixed color: third party interacting molecule. Interactome network for the differentially expressed genes extracted using the Shortest Path algorithm.

of $\mathrm{APOH}$, which is involved in blood coagulation. An association between vascular risk factors of cardiac disease and RLS has previously been established. ${ }^{41-43}$ Our findings provide additional evidence supporting a relationship and shared mechanisms between RLS and cardiovascular disease.

Another protein that we found substantially increased was leucine-rich alpha-2-glycoprotein 1 . This leucine-rich repeat molecule acts as an acute-phase protein and inflammatory marker, ${ }^{44}$ with elevated plasma levels observed in inflammatory diseases. ${ }^{45}$ As such, it has also been proposed as a biomarker for heart failure ${ }^{46}$ and neurodegenerative diseases. ${ }^{47}$ In patients with diabetes mellitus, elevated blood levels of this protein have been strongly associated with albuminuria and progression of diabetic chronic kidney disease. ${ }^{48}$ The association between RLS 
and diabetes can possibly be directional, with both conditions exacerbating each other.

Our proteomic evaluations also showed higher expression of serum extracellular matrix protein (ECM1) in patients with RLS. ECM1 plays an integral role in the positive and negative regulation of hepcidin, particularly in a tumor setting. ${ }^{49}$ Hepcidin, a peptide hormone that negatively regulates iron efflux, ${ }^{50}$ is a potential prognostic biomarker for RLS. In fact, one study comparing 65 females with primary RLS to matched controls showed higher serum hepcidin quantified via mass spectrometry; in particular, hepcidin levels reflected RLS clinical severity in a U-shaped curve relationship. ${ }^{36,51}$ This reemphasizes the primary role of iron and its metabolism in the pathophysiology of RLS.

From our analysis, among differentially downregulated proteins in the serum of patients with RLS, it appears relevant to have found changes in DBP. Proteomic analysis of CSF from patients with RLS identified also a differential expression of DBP, yet with a characteristic upregulation postulated to reflect the activation of immune cascades in the central nervous system. ${ }^{32}$ Likewise, upregulation of DBP was reported in the serum of a very small sample of RLS patients. ${ }^{35}$ Along with its role in regulating vitamin D metabolites, DBP scavenges toxins released during cell injury $^{52}$ and modulates the immune response. ${ }^{53}$ In addition, variations of its level of expression in the CSF has been associated with multiple neurodegenerative disorders, including Parkinson's disease and multiple sclerosis. ${ }^{54,55}$ Moreover, vitamin D has been postulated to contribute to the etiology of RLS and several studies performed comparative analysis of vitamin D plasma levels in patients with RLS and healthy controls. Balaban et $\mathrm{al}^{56}$ have reported lower levels of serum 25 hydroxyvitamin D in 36 female patients with RLS compared to controls. In a cross-sectional study of 57 patients with vitamin D deficiency and 45 healthy controls, RLS incidence was found to be higher in the former group. ${ }^{57} \mathrm{In}$ another study of 155 matched patients divided according to their serum 25-hydroxyvitamin D level and compared for the presence of RLS diagnostic criteria, vitamin D deficiency was significantly associated with the presence of RLS. ${ }^{58}$ Similarly, in a study involving 201 participants, the odds ratio of the development of RLS was 4.24 for those with a vitamin $\mathrm{D}$ deficiency (level $<50$ $\mathrm{nmol} / \mathrm{L}){ }^{59}$ These several lines of evidence support the idea that iron deficiency in RLS might affect central dopaminergic activity via a vitamin-D mediated pathway. ${ }^{56}$
Moreover, in terms of vitamin-D related genes, individuals with the rs731236AA genotype or carriers of the rs731236A allelic variant of the vitamin D receptor gene had a decreased risk of RLS, while those with the rs731236GG genotype had higher severity of RLS. ${ }^{60}$ Our findings, therefore, further support the pluripotential role of vitamin D and its receptors in the pathophysiology of RLS. The observed evidence of a dysregulated Vitamin D pathway is of further interest in consideration of the emerging data indicating that RLS during pregnancy might be linked to Vitamin D deficiency, and is associated with adverse pregnancy outcomes. ${ }^{61-63}$ This is a critical area for future investigation.

In line with the results of the proteomic analysis by Bellei et al, ${ }^{33}$ in our study, the concentration of $\mathrm{A}_{1} \mathrm{AT}$ was substantial in RLS patients. $A_{1}$ AT has pleiotropic effects, having been shown an association with pathways of inflammation, memory disorders, pregnancy, and cardiovascular disease as well as activation of antioxidant enzymes, suppression of oxidation stress, and decrease apoptosis. ${ }^{64}$ In a recent systematic review of blood proteomic studies of Alzheimer's disease, $\mathrm{A}_{1}$ AT was identified as a candidate biomarker. ${ }^{65}$ In pre-eclampsia, it functions as a protective factor: this is mediated by an inhibition of p38 mitogen-activated protein kinase p38MAPK signaling pathway ${ }^{66}$ and activation of Smad2 and Id4 genes, ${ }^{67}$ allowing maintenance of the vascular function during pregnancy. In terms of cardiac risk, the literature pinpoints a correlation between $\mathrm{A}_{1} \mathrm{AT}$ and cardiovascular disorders. ${ }^{68}$ As $\mathrm{A}_{1} \mathrm{AT}$ has a protective role in regulating vascular smooth muscle cells and decreasing vascular damage, a low serum level is associated with increased risk of developing arteriosclerosis. ${ }^{69}$

Another protein we found significantly downregulated in patients with RLS is Hp, an inflammation acute-phase protein with immunomodulatory and anti-inflammatory properties. ${ }^{70}$ By binding to free hemoglobin, it prevents the iron-driven formation of reactive oxygen species and oxidative tissue damage, ${ }^{71}$ and elevated $\mathrm{Hp}$ levels are observed in chronic inflammatory conditions associated with increased oxidative stress. ${ }^{72,73}$ In addition, Hp has been stated as a marker for diabetes mellitus and its complications. $^{74}$ This is prominently denoted in Figure $1 \mathrm{~A}$ and $\mathrm{D}$. In the study by Bellei et al, ${ }^{33} \mathrm{Hp}$ was characteristically found to be upregulated; The discrepant results may result from the inclusion in this study of RLS patients on medications, which might have affected the results of the proteomic analysis. In our study, the 
differential regulation of $\mathrm{Hp}$ might be also related to a chronic inflammatory milieu involved in the modulation of RLS. ${ }^{75}$ This certainly needs to be better studied in the future, also by taking into consideration the influential role of the presence of a high number of periodic leg movements during sleep in these patients. ${ }^{76}$ We also found another protein, CFHR1, to be downregulated in patients with RLS, in agreement with the previous findings by Bellei et al. ${ }^{33}$ The complement system directly regulates inflammatory processes and maintains associated homeostasis; ${ }^{77}$ thus, any alteration in this system is potentially able to worsen inflammation. This further reinforces the importance to better define the role of inflammation in RLS, also because it might represent an important target for the development of new therapeutic strategies.

Plasma protease $\mathrm{C} 1$ inhibitor levels were also significantly low in our patients with RLS compared to controls. By regulating $\mathrm{C} 1$ complex and inhibiting chymotrypsin and kallikrein, plasma protease $\mathrm{C} 1$ inhibitor plays a crucial role in fibrinolysis and downregulation, again, of inflammation. ${ }^{78,79}$ SERPING1 has been reported to be a sensitive and specific ( $>80 \%$ ) biomarker for diagnosing type I diabetes mellitus (Figure 1D). ${ }^{80}$ It was also found to be significantly associated with IGF binding protein 1, a biomarker of type II diabetes mellitus, with processes related to the immune function, oxidative stress, and cellular death. ${ }^{81}$

The other identified differentially expressed proteins, CD5L, FGA, and PF4, are associated with inflammation, neuropathology, complications of pregnancy, cardiovascular dysfunction, and diabetes mellitus. More specifically, CD5L has been demonstrated to be involved in inflammation, kidney diseases, cardiovascular diseases, diabetes, and cancers, ${ }^{82}$ PF4 has been reported to mediate inflammation, ${ }^{83}$ while FGA has been related to trauma, pregnancy, or tissue inflammation and clotting-related disorders. ${ }^{84}$ Noticeably, it is necessary to take into consideration that FGA is one of the proteins depleted by the MARS14 column. The detection of FGA in this study was because the depletion efficiency of FGA was not perfect. ${ }^{85}$ Hence, despite we observed a significant change in abundance of FGA among the different groups, this difference might have been caused by the bias introduced by the depletion steps. More investigations need to be performed for the expressions of FGA in RLS in future studies.

Interestingly, we identified three proteins: protein that is highly similar to homo sapiens C-type lectin domain family 3 (FLJ92374), protein that is highly similar to homo sapiens complement component 7 (FLJ93143), and protein that is highly similar to human $\mathrm{MHC}$ class III complement component C6 (FLJ78071), that have not been proven at proteomic levels before. According to UniProt database (www.uniprot.org), and NCBI gene bank (www.ncbi.nlm.nih.gov), the existence of these proteins was only based on the experimental evidence at transcript level. The up-regulations of FLJ92374 and FLJ93143 and the down-regulation of FLJ78071 were observed in RLS samples, indicating the necessity of investigation of these proteins in further studies.

\section{Limitations and Strengths}

Our study has some limitations. Due to the limited number of participants in each group, our findings should be interpreted with caution. We accounted for this drawback by adopting stringent recruitment criteria, with participants being off medications in order to avoid potential confounding effects on the proteomic analysis. Nonetheless, further analyses in larger cohorts applying complementary validation techniques and exploring the influence of factors that may contribute to proteome changes are necessary. Another limitation is that the low number of patients recruited precludes correlation analysis with the disease severity. It will be important to study this clinical characteristic, which coupled with an analysis of the degree of fold change in protein expression, might indicate a potential value to objectively assess the neurobiological severity of RLS.

\section{Conclusion}

In summary, we have performed an in-depth rigorous blood-based proteome profiling of non-treated patients with RLS, providing initial evidence of a detectable disease-specific molecular phenotype associated with inflammation, oxidative stress, cardiovascular disease, and metabolic dysfunction. Altogether, our data shed new light on the multifactorial nature of RLS, indicating that multiple and diverse pathophysiological mechanisms are involved in this complex disorder. This ultimately suggests that future therapeutic and intervention strategies for patients with RLS may need to be pleiotropic and multitargeted, in order to be clinically effective.

\section{Data Sharing Statement}

The authors confirm that the data supporting the findings of this study are available within the article and/or Table S1. 


\section{Acknowledgments}

This was not an industry-supported study. This work was performed at the Oasi Research Institute - IRCCS, Troina, Italy and at the Department of Chemistry and Biochemistry, Texas Tech University, Lubbock, Texas, 79409, USA. This study was partially supported by a fund from the Italian Ministry of Health "Ricerca Corrente" (RC n. 2634472) (F.I.I.C., R.F.).

\section{Disclosure}

Dr Giuseppe Plazzi reports personal fees from Jazz Pharmaceuticals, IDORSIA, Takeda, UCB, and Bioprojet, outside the submitted work. The authors report no other potential conflicts of interest in this work.

\section{References}

1. Allen RP, Picchietti DL, Garcia-Borreguero D, et al. Restless legs syndrome/Willis-Ekbom disease diagnostic criteria: updated International Restless Legs Syndrome Study Group (IRLSSG) consensus criteria--history, rationale, description, and significance. Sleep Med. 2014;15(8):860-873. doi:10.1016/j.sleep.2014.03.025

2. Allen RP, Walters AS, Montplaisir J, et al. Restless legs syndrome prevalence and impact: REST general population study. Arch Intern Med. 2005;165(11):1286-1292. doi:10.1001/archinte.165.11.1286

3. Tison F, Crochard A, Leger D, Bouee S, Lainey E, El Hasnaoui A. Epidemiology of restless legs syndrome in French adults: a nationwide survey: the INSTANT Study. Neurology. 2005;65 (2):239-246. doi:10.1212/01.wnl.0000168910.48309.4a

4. Abetz L, Allen R, Follet A, et al. Evaluating the quality of life of patients with restless legs syndrome. Clin Ther. 2004;26(6):925-935. doi:10.1016/S0149-2918(04)90136-1

5. Walters AS, Rye DB. Review of the relationship of restless legs syndrome and periodic limb movements in sleep to hypertension, heart disease, and stroke. Sleep. 2009;32(5):589-597. doi:10.1093/ sleep/32.5.589

6. Schilling C, Schredl M, Strobl P, Deuschle M. Restless legs syndrome: evidence for nocturnal hypothalamic-pituitary-adrenal system activation. Mov Disord. 2010;25(8):1047-1052. doi:10.1002/mds.23026

7. Dauvilliers Y, Winkelmann J. Restless legs syndrome: update on pathogenesis. Curr Opin Pulm Med. 2013;19(6):594-600. doi:10.1097/MCP.0b013e328365ab07

8. Earley CJ, Connor J, Garcia-Borreguero D, et al. Altered brain iron homeostasis and dopaminergic function in restless legs syndrome (Willis-Ekbom disease). Sleep Med. 2014;15(11):1288-1301. doi:10.1016/j.sleep.2014.05.009

9. Staedt J, Stoppe G, Kogler A, et al. Dopamine D2 receptor alteration in patients with periodic movements in sleep (nocturnal myoclonus). $J$ Neural Transm Gen Sect. 1993;93(1):71-74. doi:10.1007/ BF01244940

10. Turjanski N, Lees AJ, Brooks DJ. Striatal dopaminergic function in restless legs syndrome: 18F-dopa and 11C-raclopride PET studies. Neurology. 1999;52(5):932-937. doi:10.1212/WNL.52.5.932

11. Michaud M, Soucy JP, Chabli A, Lavigne G, Montplaisir J. SPECT imaging of striatal pre- and postsynaptic dopaminergic status in restless legs syndrome with periodic leg movements in sleep. J Neurol. 2002;249(2):164-170. doi:10.1007/PL00007859
12. Brodeur C, Montplaisir J, Godbout R, Marinier R. Treatment of restless legs syndrome and periodic movements during sleep with L-dopa: a double-blind, controlled study. Neurology. 1988;38 (12):1845-1848. doi:10.1212/WNL.38.12.1845

13. Earley CJ, Yaffee JB, Allen RP. Randomized, double-blind, placebo-controlled trial of pergolide in restless legs syndrome. Neurology. 1998;51(6):1599-1602. doi:10.1212/WNL.51.6.1599

14. Wetter TC, Stiasny K, Winkelmann J, et al. A randomized controlled study of pergolide in patients with restless legs syndrome. Neurology. 1999;52(5):944-950. doi:10.1212/WNL.52.5.944

15. Montplaisir J, Nicolas A, Denesle R, Gomez-Mancilla B. Restless legs syndrome improved by pramipexole: a double-blind randomized trial. Neurology. 1999;52(5):938-943. doi:10.1212/WNL.52.5.938

16. Silber MH, Becker PM, Earley C, Garcia-Borreguero D, Ondo WG. Medical advisory board of the Willis-Ekbom disease F. Willis-Ekbom Disease Foundation revised consensus statement on the management of restless legs syndrome. Mayo Clin Proc. 2013;88(9):977-986. doi:10.1016/j.mayocp.2013.06.016

17. Garcia-Borreguero D, Kohnen R, Silber MH, et al. The long-term treatment of restless legs syndrome/Willis-Ekbom disease: evidence-based guidelines and clinical consensus best practice guidance: a report from the International Restless Legs Syndrome Study Group. Sleep Med. 2013;14(7):675-684. doi:10.1016/j. sleep.2013.05.016

18. Allen RP. Controversies and challenges in defining the etiology and pathophysiology of restless legs syndrome. Am J Med. 2007;120(1 Suppl 1):S13-S21. doi:10.1016/j.amjmed.2006.11.003

19. Earley CJ, Kuwabara H, Wong DF, et al. The dopamine transporter is decreased in the striatum of subjects with restless legs syndrome. Sleep. 2011;34(3):341-347. doi:10.1093/sleep/34.3.341

20. Allen RP, Barker PB, Wehrl FW, Song HK, Earley CJ. MRI measurement of brain iron in patients with restless legs syndrome. Neurology. 2001;56(2):263-265. doi:10.1212/WNL.56.2.263

21. Earley CJ, Connor JR, Beard JL, Malecki EA, Epstein DK, Allen RP. Abnormalities in CSF concentrations of ferritin and transferrin in restless legs syndrome. Neurology. 2000;54(8):1698-1700. doi:10.1212/WNL.54.8.1698

22. Connor JR, Boyer PJ, Menzies SL, et al. Neuropathological examination suggests impaired brain iron acquisition in restless legs syndrome. Neurology. 2003;61(3):304-309. doi:10.1212/01. WNL.0000078887.16593.12

23. Li X, Allen RP, Earley CJ, et al. Brain iron deficiency in idiopathic restless legs syndrome measured by quantitative magnetic susceptibility at 7 tesla. Sleep Med. 2016;22:75-82. doi:10.1016/j. sleep.2016.05.001

24. Allen RP, Picchietti D, Hening WA, et al. Restless legs syndrome: diagnostic criteria, special considerations, and epidemiology. A report from the restless legs syndrome diagnosis and epidemiology workshop at the National Institutes of Health. Sleep Med. 2003;4 (2):101-119. doi:10.1016/S1389-9457(03)00010-8

25. Nagandla K, De S. Restless legs syndrome: pathophysiology and modern management. Postgrad Med J. 2013;89(1053):402-410. doi:10.1136/postgradmedj-2012-131634

26. Fawaz CN, Makki IS, Kazan JM, et al. Neuroproteomics and microRNAs studies in multiple sclerosis: transforming research and clinical knowledge in biomarker research. Expert Rev Proteomics. 2015;12(6):637-650. doi:10.1586/14789450.2015.1099435

27. Jaber Z, Aouad P, Al Medawar M, et al. Role of systems biology in brain injury biomarker discovery: neuroproteomics application. Methods Mol Biol. 2016;1462:157-174.

28. Kim MS, Pinto SM, Getnet D, et al. A draft map of the human proteome. Nature. 2014;509(7502):575-581. doi:10.1038/ nature 13302 
29. Mondello S, Kobeissy F, Mechref Y, et al. Novel biomarker signatures for idiopathic REM sleep behavior disorder: a proteomic and system biology approach. Neurology. 2018;91(18):e1710-e1715. doi:10.1212/WNL.0000000000006439

30. Azar S, Hasan A, Younes R, et al. Biofluid proteomics and biomarkers in traumatic brain injury. Methods Mol Biol. 2017;1598:45-63.

31. Mondello S, Muller U, Jeromin A, Streeter J, Hayes RL, Wang KK. Blood-based diagnostics of traumatic brain injuries. Expert Rev Mol Diagn. 2011;11(1):65-78. doi:10.1586/erm.10.104

32. Patton SM, Cho YW, Clardy TW, Allen RP, Earley CJ, Connor JR. Proteomic analysis of the cerebrospinal fluid of patients with restless legs syndrome/Willis-Ekbom disease. Fluids Barriers CNS. 2013;10 (1):20. doi:10.1186/2045-8118-10-20

33. Bellei E, Monari E, Ozben S, et al. Discovery of restless legs syndrome plasmatic biomarkers by proteomic analysis. Brain Behav. 2018;8(10):e01062. doi:10.1002/brb3.1062

34. Bellei E, Bergamini S, Monari E, et al. Evaluation of potential cardiovascular risk protein biomarkers in high severity restless legs syndrome. J Neural Transm. 2019;126(10):1313-1320. doi:10.1007/ s00702-019-02051-7

35. Shin JW, Lee JH, Kim H, et al. Bioinformatic analysis of proteomic data for iron, inflammation, and hypoxic pathways in restless legs syndrome. Sleep Med. 2020;75:448-455. doi:10.1016/j. sleep.2020.09.002

36. Chenini S, Delaby C, Rassu AL, et al. Hepcidin and ferritin levels in restless legs syndrome: a case-control study. Sci Rep. 2020;10 (1):11914. doi:10.1038/s41598-020-68851-0

37. Kohn EC, Azad N, Annunziata C, Dhamoon AS, Whiteley G. Proteomics as a tool for biomarker discovery. Dis Markers. 2007;23 (5-6):411-417. doi:10.1155/2007/967023

38. Walters AS, LeBrocq C, Dhar A, et al. Validation of the International Restless Legs Syndrome Study Group rating scale for restless legs syndrome. Sleep Med. 2003;4(2):121-132.

39. Mondello S, Kobeissy F, Vestri A, Hayes RL, Kochanek PM, Berger RP. Serum concentrations of ubiquitin C-terminal hydrolase-L1 and glial fibrillary acidic protein after pediatric traumatic brain injury. Sci Rep. 2016;6:28203. doi:10.1038/srep28203

40. Kei AA, Filippatos TD, Tsimihodimos V, Elisaf MS. A review of the role of apolipoprotein C-II in lipoprotein metabolism and cardiovascular disease. Metabolism. 2012;61(7):906-921. doi:10.1016/j. metabol.2011.12.002

41. Winter AC, Berger K, Glynn RJ, et al. Vascular risk factors, cardiovascular disease, and restless legs syndrome in men. Am J Med. 2013;126(3):228-235, $235 \quad$ e221-222. doi:10.1016/j. amjmed.2012.06.039

42. Schlesinger I, Erikh I, Avizohar O, Sprecher E, Yarnitsky D. Cardiovascular risk factors in restless legs syndrome. Mov Disord. 2009;24(11):1587-1592. doi:10.1002/mds.22486

43. Trenkwalder C, Allen R, Hogl B, et al. Comorbidities, treatment, and pathophysiology in restless legs syndrome. Lancet Neurol. 2018;17 (11):994-1005. doi:10.1016/S1474-4422(18)30311-9

44. Shirai R, Hirano F, Ohkura N, Ikeda K, Inoue S. Up-regulation of the expression of leucine-rich alpha(2)-glycoprotein in hepatocytes by the mediators of acute-phase response. Biochem Biophys Res Commun. 2009;382(4):776-779. doi:10.1016/j.bbrc.2009.03.104

45. Serada S, Fujimoto M, Ogata A, et al. iTRAQ-based proteomic identification of leucine-rich alpha-2 glycoprotein as a novel inflammatory biomarker in autoimmune diseases. Ann Rheum Dis. 2010;69 (4):770-774. doi:10.1136/ard.2009.118919

46. Watson CJ, Ledwidge MT, Phelan D, et al. Proteomic analysis of coronary sinus serum reveals leucine-rich alpha 2-glycoprotein as a novel biomarker of ventricular dysfunction and heart failure. Circ Heart Fail. 2011;4 (2):188-197. doi:10.1161/CIRCHEARTFAILURE.110.952200
47. Miyajima M, Nakajima M, Motoi $Y$, et al. Leucine-rich alpha 2-glycoprotein is a novel biomarker of neurodegenerative disease in human cerebrospinal fluid and causes neurodegeneration in mouse cerebral cortex. PLoS One. 2013;8(9):e74453. doi:10.1371/journal. pone. 0074453

48. Liu JJ, Pek SLT, Ang K, Tavintharan S, Lim SC, study SD. Plasma leucine-rich alpha-2-glycoprotein 1 predicts rapid eGFR decline and albuminuria progression in type 2 diabetes mellitus. $J$ Clin Endocrinol Metab. 2017;102(10):3683-3691. doi:10.1210/jc.201700930

49. Blanchette N, Tesfay L, Kita D, Claffey KP, Torti FM, Torti SV. A novel role for the extracellular matrix in regulation of hepcidin in breast cancer spheroids. FASEB J. 2016;30 (1_supplement):1099-1107.

50. Ganz T, Nemeth E. Hepcidin and iron homeostasis. Biochim Biophys Acta. 2012;1823(9):1434-1443. doi:10.1016/j.bbamcr.2012.01.014

51. Dauvilliers Y, Chenini S, Vialaret J, et al. Association between serum hepcidin level and restless legs syndrome. Mov Disord. 2018;33 (4):618-627. doi:10.1002/mds.27287

52. Speeckaert M, Huang G, Delanghe JR, Taes YE. Biological and clinical aspects of the vitamin D binding protein (Gc-globulin) and its polymorphism. Clin Chim Acta. 2006;372(1-2):33-42. doi:10.1016/j.cca.2006.03.011

53. Gomme PT, Bertolini J. Therapeutic potential of vitamin D-binding protein. Trends Biotechnol. 2004;22(7):340-345. doi:10.1016/j. tibtech.2004.05.001

54. Qin Z, Qin Y, Liu S. Alteration of DBP levels in CSF of patients with MS by proteomics analysis. Cell Mol Neurobiol. 2009;29 (2):203-210. doi:10.1007/s10571-008-9312-z

55. Zhang J, Sokal I, Peskind ER, et al. CSF multianalyte profile distinguishes Alzheimer and Parkinson diseases. Am J Clin Pathol. 2008;129(4):526-529. doi:10.1309/W01Y0B808EMEH12L

56. Balaban H, Yildiz OK, Cil G, et al. Serum 25-hydroxyvitamin D levels in restless legs syndrome patients. Sleep Med. 2012;13 (7):953-957. doi:10.1016/j.sleep.2012.04.009

57. Cakir T, Dogan G, Subasi V, et al. An evaluation of sleep quality and the prevalence of restless leg syndrome in vitamin D deficiency. Acta Neurol Belg. 2015;115(4):623-627. doi:10.1007/s13760-0150474-4

58. Oran M, Unsal C, Albayrak Y, et al. Possible association between vitamin D deficiency and restless legs syndrome. Neuropsychiatr Dis Treat. 2014;10:953-958. doi:10.2147/NDT.S63599

59. Wali S, Alsafadi S, Abaalkhail B, et al. The association between vitamin D level and restless legs syndrome: a Population-Based Case-Control Study. J Clin Sleep Med. 2018;14(4):557-564. doi: $10.5664 / \mathrm{jcsm} .7044$

60. Jimenez-Jimenez FJ, Garcia-Martin E, Alonso-Navarro H, et al. Association between vitamin D receptor rs 731236 (Taq1) polymorphism and risk for restless legs syndrome in the Spanish caucasian population. Medicine. 2015;94(47):e2125. doi:10.1097/ MD.0000000000002125

61. Almeneessie AS, Alyousefi N, Alzahrani M, et al. Prevalence of restless legs syndrome among pregnant women: a case-control study. Ann Thorac Med. 2020;15(1):9-14. doi:10.4103/atm. ATM_206_19

62. Picchietti DL, Hensley JG, Bainbridge JL, et al. Consensus clinical practice guidelines for the diagnosis and treatment of restless legs syndrome/Willis-Ekbom disease during pregnancy and lactation. Sleep Med Rev. 2015;22:64-77.

63. Gupta R, Dhyani M, Kendzerska T, et al. Restless legs syndrome and pregnancy: prevalence, possible pathophysiological mechanisms and treatment. Acta Neurol Scand. 2016;133(5):320-329. doi:10.1111/ ane. 12520 
64. Feng Y, Hu L, Xu Q, et al. Cytoprotective role of alpha-1 antitrypsin in vascular endothelial cell under hypoxia/reoxygenation condition. J Cardiovasc Pharmacol. 2015;66(1):96-107. doi:10.1097/ FJC.0000000000000250

65. Kiddle SJ, Sattlecker M, Proitsi P, et al. Candidate blood proteome markers of alzheimer's disease onset and progression: a systematic review and replication study. J Alzheimers Dis. 2014;38(3):515-531. doi:10.3233/JAD-130380

66. Feng YL, Yin YX, Ding J, et al. Alpha-1-antitrypsin suppresses oxidative stress in preeclampsia by inhibiting the p38MAPK signaling pathway: an in vivo and in vitro study. PLoS One. 2017;12(3): e0173711. doi:10.1371/journal.pone.0173711

67. Feng Y, Wang N, Xu J, et al. Alpha-1-antitrypsin functions as a protective factor in preeclampsia through activating Smad2 and inhibitor of DNA binding 4. Oncotarget. 2017;8(68):113002-113012. doi:10.18632/oncotarget.22949

68. Fahndrich S, Biertz F, Karch A, et al. Cardiovascular risk in patients with alpha-1-antitrypsin deficiency. Respir Res. 2017;18(1):171. doi:10.1186/s12931-017-0655-1

69. Duckers JM, Shale DJ, Stockley RA, et al. Cardiovascular and musculskeletal co-morbidities in patients with alpha 1 antitrypsin deficiency. Respir Res. 2010;11:173. doi:10.1186/1465-9921-11-173

70. Gabay C, Kushner I, Epstein FH. Acute-phase proteins and other systemic responses to inflammation. $N$ Engl J Med. 1999;340 (6):448-454. doi:10.1056/NEJM199902113400607

71. Lim SK, Kim H, Lim SK, et al. Increased susceptibility in Hp knockout mice during acute hemolysis. Blood. 1998;92 (6):1870-1877. doi:10.1182/blood.V92.6.1870

72. Nakhoul FM, Miller-Lotan R, Awaad H, Asleh R, Levy AP. Hypothesis-haptoglobin genotype and diabetic nephropathy. Nat Clin Pract Nephrol. 2007;3(6):339-344. doi:10.1038/ncpneph0467

73. Quaye IK. Haptoglobin, inflammation and disease. Trans $R$ Soc Trop Med Hyg. 2008;102(8):735-742. doi:10.1016/j.trstmh.2008.04.010

74. Kruger AJ, Yang C, Tam SW, et al. Haptoglobin as an early serum biomarker of virus-induced autoimmune type 1 diabetes in biobreeding diabetes resistant and LEW1.WR1 rats. Exp Biol Med (Maywood). 2010;235(11):1328-1337. doi:10.1258/ebm.2010.010150

75. Varim C, Acar BA, Uyanik MS, et al. Association between the neutrophil-to-lymphocyte ratio, a new marker of systemic inflammation, and restless legs syndrome. Singapore Med J. 2016;57 (9):514-516. doi:10.11622/smedj.2016154
76. Trotti LM, Rye DB, De Staercke C, Hooper WC, Quyyumi A, Bliwise DL. Elevated C-reactive protein is associated with severe periodic leg movements of sleep in patients with restless legs syndrome. Brain Behav Immun. 2012;26(8):1239-1243. doi:10.1016/j.bbi.2012.06.003

77. Ricklin D, Hajishengallis G, Yang K, Lambris JD. Complement: a key system for immune surveillance and homeostasis. Nat Immunol. 2010;11(9):785-797. doi:10.1038/ni.1923

78. Davis AE 3rd, Mejia P, Lu F. Biological activities of $\mathrm{C} 1$ inhibitor. Mol Immunol. 2008;45(16):4057-4063. doi:10.1016/j. molimm.2008.06.028

79. Stoermer KA, Morrison TE. Complement and viral pathogenesis. Virology. 2011;411(2):362-373. doi:10.1016/j.virol.2010.12.045

80. Zhang Q, Fillmore TL, Schepmoes AA, et al. Serum proteomics reveals systemic dysregulation of innate immunity in type 1 diabetes. $J$ Exp Med. 2013;210(1):191-203. doi:10.1084/ jem.20111843

81. Ahluwalia TS, Allin KH, Sandholt $\mathrm{CH}$, et al. Discovery of coding genetic variants influencing diabetes-related serum biomarkers and their impact on risk of type 2 diabetes. J Clin Endocrinol Metab. 2015;100(4):E664-E671. doi:10.1210/jc.2014-3677

82. Sanjurjo L, Aran G, Roher N, Valledor AF, Sarrias MR. AIM/CD5L: a key protein in the control of immune homeostasis and inflammatory disease. J Leukoc Biol. 2015;98(2):173-184. doi:10.1189/ jlb.3RU0215-074R

83. Shi G, Morrell CN. Platelets as initiators and mediators of inflammation at the vessel wall. Thromb Res. 2011;127(5):387-390. doi:10.1016/j.thromres.2010.10.019

84. Chapman J, Dogan A. Fibrinogen alpha amyloidosis: insights from proteomics. Expert Rev Proteomics. 2019;16(9):783-793. doi:10.1080/14789450.2019.1659137

85. Palstrom NB, Rasmussen LM, Beck HC. Affinity capture enrichment versus affinity depletion: a comparison of strategies for increasing coverage of low-abundant human plasma proteins. Int $J \mathrm{Mol} \mathrm{Sci}$. 2020;21(16):5903. doi:10.3390/ijms21165903

\section{Publish your work in this journal}

Nature and Science of Sleep is an international, peer-reviewed, open access journal covering all aspects of sleep science and sleep medicine, including the neurophysiology and functions of sleep, the genetics of sleep, sleep and society, biological rhythms, dreaming, sleep disorders and therapy, and strategies to optimize healthy sleep.
The manuscript management system is completely online and includes a very quick and fair peer-review system, which is all easy to use. Visit http://www.dovepress.com/testimonials.php to read real quotes from published authors. 